\title{
A Holistic Approach for Enhancing Distributed Education with Multi-Campus Course Delivery Methods
}

\author{
Dr. Mahmoud K Quweider, University of Texas, Rio Grande Valley
}

M K Quweider is a Professor of Computer \& Information Sciences at the U. of Texas at UTRGV. He received his Ph.D. in Engineering Science (Multimedia and Imaging Specialty) and B.S. In Electrical Engineering, M.S. in Applied Mathematics, M.S. in Engineering Science, and M.S. in Biomedical Engineering all from the University of Toledo, Ohio. He also holds a Bachelor of English and a Masters of Business Administration from the University of Texas at Brownsville. After graduation, he was employed at several corporations including Pixera, a digital multimedia processing company in Cupertino, CA, 3COM, a networking and communication company in Schaumberg, IL, and Mercantec, an E-Commerce company in Naperville, IL. He has more than 40 publications in the field, and has served as a reviewer/moderator for several scientific and educational journals and conferences. He joined UTB in the Spring of 2000. His areas of interest include Imaging, Visualization and Animation, Networking and Cyber Security, Web Design, Computer Graphics, and Linguistics.

\section{Dr. Ala Qubbaj, University of Texas, Rio Grande Valley}

Ala Qubbaj, Ph.D. Dean of the College of Engineering \& Computer Science The University of Texas Rio Grande Valley Dr. Ala Qubbaj is the Dean for the College of Engineering and Computer Science at the University of Texas Rio Grande Valley (UTRGV) and the Principle Investigator (PI) for the UTRGV's ADVANCE Institutional Transformation grant funded by the National Science Foundation (NSF); which focuses on increasing the representation and advancement of women in STEM fields. He is also the PI on an NSF INCLUDES (Inclusion across the Nation of Communities of Learners of Underrepresented Discoverers in Engineering and Science) project/Symposium for ADVANCING STEM Latinas in Academic Careers.

Prior to his Dean position, Dr. Qubbaj served as Senior Associate Vice President/Vice Provost for Faculty Affairs \& Diversity at UTRGV. He is also a full professor in the department of Mechanical Engineering. Dr. Qubbaj received his Ph.D. from the University of Oklahoma with specialization in combustion and energy system. His research has been sponsored by NSF, the Department of Energy, and the Department of Defense.

\section{Liyu Zhang, University of Texas Rio Grande Valley}

Liyu Zhang is an Associate Professor in the Department of Computer Science Department of Computer Science at the University of Texas Rio Grande Valley. He received his Ph. D. in Computer Science from the State University of New York at Buffalo in September 2007. Before that he received his M. S. (2000) and B. S. (1997) from Fudan University, Shanghai , China, both in Computer Science. His research interests are in theoretical computer science and its applications, with emphasis on computational complexity, complexity-based cryptography, and design and analysis of algorithms. Dr. Zhang's research has been sponsored by National Science Foundation and U.S. Department of Education.

\section{Dr. Fitratullah Khan, The University of Texas Rio Grande Valley}

Professor Fitratullah Khan has been teaching computer science courses since 1992. His areas of expertise are computer architecture, networking, database systems, computing platforms and languages. As the director of Infrastructure, Telecommunications, and Networking (ITNet), and later as a Chief Technology Officer, at UT Brownsville, he implemented state of the art networking using campus wide fiber ring with redundant links. He established diskless computer labs to provide uniform computing platform across campus, and modernized classrooms to make them congenial to online learning. He was the PI on NSF funded BCEIL (Beowulf-based Curriculum Enrichment Integrated Laboratory) and Co-PI on NSF funded MCALL (Multimedia based Computer Assisted Learning Lab).

\section{Dr. Hansheng Lei}




\title{
A Holistic Approach for Enhancing Distributed Education with Multi-Campus Course Delivery Methods
}

\begin{abstract}
To create an emerging teaching and research institution, a regional university was created that spans multiple campuses located over an area of hundred miles across the Rio Grande Valley by merging at least three current institutions. The merge allowed the university to pool its human and technical resources. Students can now pursue new degrees that were not available before at one campus or another, take newly available technical or specialty courses, and even select their own preferred professor when a course is offered by many faculty.

In order to serve students at multiple campuses that are geographically far apart, the university instituted policies to facilitate accessibility of courses to all students while meeting prerequisites and minimum enrollment requirements. This paper chronicles the policies, procedures, and faculty and staff efforts in creating a sustainable framework for implementing a distributed campus course delivery that is acceptable by the university/college administration, the department, the faculty, and most importantly the students. Our experience shows that a successful framework should address many issues, including: Logistics, Scheduling, Faculty incentives, IT support, course management system and delivery methods, assessment and student participation. The paper will present our efforts in each of the above areas, showing that despite the challenges faced, a distributed delivery system can be successful when the above issues/factors are adequately addressed. The results from our courses at the graduate and undergraduate levels show that student assessments don't show any significant difference across campuses or based on where the home campus of the faculty is. By presenting our study, we hope that other institutions who are considering distributed education can benefit from our experience by adopting best practices while avoiding pitfalls.
\end{abstract}

Keywords Interactive TV, Distributed Education, Course Management Systems, Video Conferencing, Social Media 


\section{Introduction \& Motivation:}

In late December of 2012, the UT (University of Texas) System Board of Regents voted to establish a new Rio-Grande Valley-wide emerging teaching and research $21^{\text {st }}$ century university that would combine the future South Texas School of Medicine, proposed at the Regional Academic Health Center in Harlingen, and the region's two universities, UTPA (The University of Texas-Pan American), located in Edinburg, and UTB (The University of Texas at Brownsville). The two campuses and center are located within a radius of roughly sixty-five miles, and as the merger process completed the new school opened for public as UTRGV (The University of Texas at the Rio Grande Valley). The remote facilities of UTPA, such as the one in Rio Grande City, and of UTB, such as the one in South Padre Island, were included in the merger, thereby creating a geographically dispersed university spanning over hundred miles across the Rio Grande Valley.

To understand the issues, discussed in this paper, it is important to present enrollment of the two campuses and the distribution of faculty on each campus at the time of the merger because they are indicative of the relative size of each institution regarding human and physical resources and the number of courses offered on each campus.

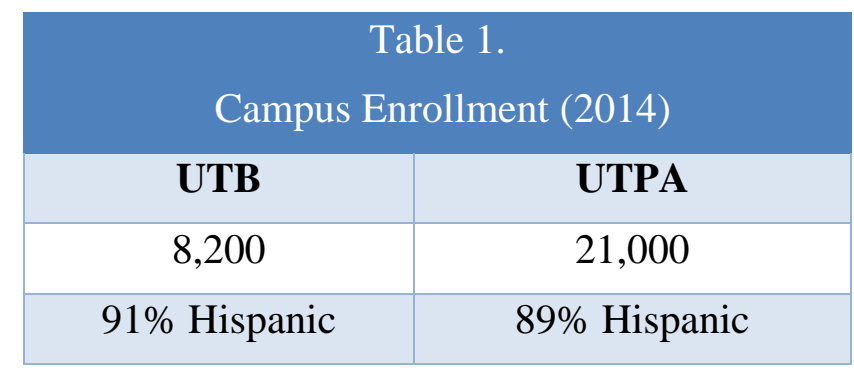

\begin{tabular}{|c|c|} 
Table 2. \\
CS Faculty at the time of the Merger \\
\hline UTB & UTPA \\
\hline 8 & 18 \\
\hline
\end{tabular}

It was soon realized that the newly consolidated distributed multi-campus university has many challenges to deal with related to recruitment, enrollment, teaching, meeting pedagogical objectives, and accreditation, to mention a few. Research has its own challenges as well, but that is left for a future study. In this paper, we address some of the challenges that the college of Engineering in general, and the Computer Science in particular, have faced related to logistics, scheduling, faculty incentives, IT support, course management system and delivery methods, and assessment and student participation. We follow this by presenting the details of offering two ITV courses across the two major campuses located in Brownsville and Edinburg during the spring of 2018, evaluating in the process the advantages, disadvantages, benefits, challenges, and student feedback gained from such a new and unique experience.

\section{Logistics}


One of the first issues that the CS department faced is where to efficiently offer the courses. In order to minimize redundancy and optimize resources, it was decided that first two-year courses will be offered at both major campuses, located in Brownsville and Edinburg. However, the same upper level courses and technical electives could not be offered at both campuses during the same semester. So, a rotation cycle was created where courses would be offered on one campus one year, and on the other the following year. With technical elective and specialty courses, not enough instructors exist at both campuses, and therefore we wanted to try Interactive TV as a good and viable alternative. On-line courses are still offered, but due to accreditation requirements, faculty have to meet more stringent quality training and enforcements. Work on on-line courses is in the works and selected courses will be offered by qualified faculty.

An ITV course is one that is offered synchronously at the same time at both campuses by using HD cameras with high speed network connection and using wireless audio mic attached to the professor as he/she lectures. The course is offered in an ITV capable classroom equipped with HD TVs installed and high fidelity speakers to allow students to watch and hear the professor lecturing from the remote site. Students can ask questions in real-time and interact with the professor despite the separating distance. To improve the experience for students, professors who teach ITV also record their lectures through some of the tools, such as Tegrity, bundled with the course management system, such as Blackboard, used at our university. The use of Tegrity recording in classes was recommended based on overwhelming student feedback and a previous study that showed that recording the lectures help in retaining students and improve their academic performance.

The use of the ITV methodology solves one of the most urgent problems for students, which is lack of time. As the distance between the two campuses is roughly 65 miles, a university bus ride, attending the class, and coming back from the other campus would take an average of six hours; three hours of travel time, an hour \& a half of class time, and an hour and a half of wait time for the bus. Such a waste of time is not acceptable for working students, and for the students who can't do other things on the bus due to medical or psychological reasons. UTRGV has improved the bus experience over the past three years of the merger, but the ITV concept is an elegant one in that it harnesses technology to solve the distance problem without the students leaving his/her home campus or making elaborate arrangements besides the class time. It is the closest thing a student gets besides the face to face class. Convenience proved high on students' reason of why they choose to take an ITV course as we will see in the case study presented in this paper.

\section{Class Scheduling}

The college and the department of CS have strived to schedule classes so that students can attend all their classes on-time without conflicts. However, as we see from the inter-campus bus schedule, such a task is daunting to say the least. To take a class at 8:00 in the morning, a student must be at the bus stop by 6:00 am, which means that the student must wake up by 5:00; that is roughly a three hour before the student gets to the class. The convenience and minimizing the ride time was one of the major factors to offer ITV courses. An ITV student can use the time in a more convenient and optimal way, even if the bus is equipped with Wi-Fi and other conveniences. 


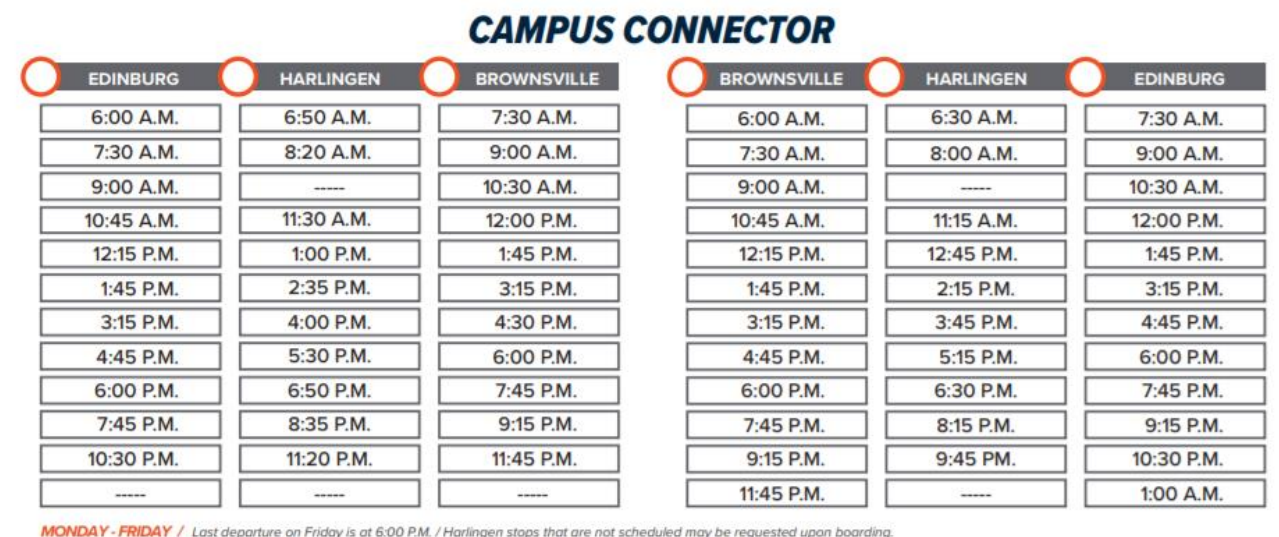

\section{Faculty Incentives}

Figure 1. Inter-Campus Bus Schedule

The university prides itself as one with a good faculty-to-student ratio. The ITV offering of courses was meant to maintain that ratio. To that effect the faculty workload computation had a formula to account for any increase in the number of students due to increased enrollment across the two major campuses.

Moreover, to maintain order, fix any IT glitches, proctor exams, and more importantly tend to any questions or class concerns from the students, every ITV professor was given one TA to be present at the other campus during class time and office hours.

\section{IT support}

As ITV is a technology demanding operation, UTRGV provided extended IT support to ensure that the quality of the courses is not affected. IT support for ITV courses include:

- $\quad$ Interactive TV with high bandwidth

- $\quad$ Podiums with Wacom tablets and Bluetooth audio speakers

- $\quad$ Tegrity recording integrated with Blackboard

- $\quad$ Virtual office through Collaborate (audio/chat/text tools)

\section{Course Management System and Delivery Methods}

As mentioned previously, Blackboard with Tegrity and Collaborate are the university's choice for the course management system. Per published course schedule, ITV course shows up as two separate courses when students register for the course. However, for educational, management and assessment purposes, the two courses are usually merged under one course with access granted to IT satff and the assigned TA for diagnostics and grading, respectively. Blackboard comes with many tools that are useful for ITV course. They include Tegrity for recording the class proceedings, Collaborate for text, chat, and audio/video conferencing during office hours. This is in addition to the grading, assessment and training tools.

Students can receive immediate notifications through announcements whenever new material or assignments are added to the course content.

\section{Assessment and student participation}


While the university and college provide formal student evaluation for all its offered classes, it was pertinent for the success of ITV classes to get feedback early in the semester, even if at an informal level. To do this, the instructors engaged the students by:

- maintaining interaction with student on daily and weekly basis,

- $\quad$ compare results of quizzes, exams, and projects from both campuses to avoid any emerging issues, and

- $\quad$ professors alternated the lecture times as circumstances allowed to get a feel for what the students are experiencing at both campuses.

Following, we present our efforts in offering ITV courses at the two campuses during the Spring semester of 2018.

\section{Case Study with ITV Courses}

We have offered two ITV courses in the Spring of 2018. The two courses offered were upper level elective courses with the expertise on the Brownsville campus. However, as we mentioned above, The Brownsville side has small enrollment numbers and it would have been hard to justify offering one of the courses with just a few students. The course numbers and levels are as follows whereas Table 3 gives the description of the courses.

- CSCI-4301 Digital Image Processing:

- CSCI-4350 Artificial Intelligence:

\begin{tabular}{|l|l|}
\hline $\begin{array}{c}\text { Prefix } \\
\text { and } \\
\text { Number }\end{array}$ & \multicolumn{1}{|c|}{$\begin{array}{c}\text { Table } 3 . \\
\text { ITV Course List and Description }\end{array}$} \\
\hline $\begin{array}{l}\text { CSCI- } \\
\text { 4301 }\end{array}$ & $\begin{array}{l}\text { Digital Image Processing: The course presents fundamental concepts } \\
\text { and applications of digital image processing. Topics include basic color, } \\
\text { image perception and transformation, image enhancement and } \\
\text { compression, and image analysis, and computer vision. Equivalent } \\
\text { course: CMPE 4301. A student may receive credit in only one course. } \\
\text { Prerequisites: CSCI 3333 or CMPE 3333. }\end{array}$ \\
\hline $\begin{array}{l}\text { CSCI- } \\
\text { 4350 }\end{array}$ & $\begin{array}{l}\text { Artificial Intelligence: Study of intelligent machines and machine } \\
\text { learning. Includes problem solving and heuristic search, natural } \\
\text { language understanding, game playing, database and expert systems. } \\
\text { Artificial Intelligence projects will be implemented using an AI language } \\
\text { such as LISP, Prolog, C++ or Ada. Equivalent course: CMPE 4350. A } \\
\text { student may receive credit in only one course. Prerequisites: CSCI 3333 } \\
\text { or CMPE 3333. }\end{array}$ \\
\hline
\end{tabular}

Class Enrollment and Grade Distribution

\begin{tabular}{|c|lr|}
\multicolumn{2}{c}{ Class Enrollment by Campus } \\
\hline Brownsville & 6 & CSCI 4350 \\
\hline
\end{tabular}


\begin{tabular}{l|l} 
Edinburg & 23
\end{tabular}

\section{Class Enrollment by Campus}

\section{CSCI 4301}

Brownsville 19

Edinburg 20

Final Grade Distribution

\begin{tabular}{|l|l|l|l|l|l|l|l|}
\hline & A & B & C & D & F & I & W/Dr \\
\hline Brownsville & 2 & 2 & 0 & 0 & 2 & 0 & 0 \\
\hline Edinburg & 6 & 5 & 3 & 1 & 4 & 0 & 4 \\
\hline
\end{tabular}

\begin{tabular}{|l|l|l|l|l|l|l|l|}
\hline & A & B & C & D & F & I & W/Dr \\
\hline Brownsville & 18 & 1 & 0 & 0 & 0 & 0 & 0 \\
\hline Edinburg & 10 & 5 & 2 & 1 & 2 & 0 & 0 \\
\hline
\end{tabular}

Among all the failed students, one student didn't submit any work and should've dropped the course, while the rest of the failed students did some but not all homework assignments until they failed the midterm exam.

Looking at the grade distribution, the results are not very conclusive to declare that the remote site is at a far greater disadvantage as far as learning outcomes are concerned. Even though most of the non-A grades were on the remote site (Edinburg), most of the A grades were earned by the students on the remote site in one course and more than one-third of the A grades were earned by the students at the remote site in the other course. More samples need to be studied over the years to get conclusive results in order to erase any gaps specific to ITV mode of delivery. Below are the percentages of each campus regarding grade distribution:

\begin{tabular}{|l|l|l|l|l|l|l|}
\hline & \multicolumn{5}{|c|}{ CSCI 4350 Artificial Intelligence } \\
\hline $\begin{array}{l}\text { Brownsville } \\
\text { \% }\end{array}$ & $25 \%$ & B & C & D & F \\
\hline Edinburg & $75 \%$ & $0 \%$ & $0 \%$ & $33 \%$ \\
\hline
\end{tabular}

\begin{tabular}{|l|l|l|l|l|l|}
\hline \multicolumn{5}{|c}{ CSCI 4301 Digital Image Processing } \\
\hline & A & B & C & D & F \\
\hline Brownsville & $64 \%$ & $17 \%$ & $0 \%$ & $0 \%$ & $0 \%$ \\
\hline Edinburg & $36 \%$ & $83 \%$ & $100 \%$ & $100 \%$ & $100 \%$ \\
\hline
\end{tabular}




\section{Technology used for class}

ITV, Collaborate and Tegrity - An ITV instructor delivered the lecture in an ITV capable classroom at the Brownsville campus while the class proceedings being live streamed to another equally ITV capable classroom at the Edinburg campus. The instructor and students at both campuses can comfortably see each other and ask/answer questions. In addition, all lecture activities on the podium computer including the voices of instructors and students were recorded through Tegrity in Blackboard so students can review them any time at their own pace. Blackboard Collaborate was used to conduct office hours in real time for the students at a distance.

\section{Resources allocated}

An ITV instructor was provided a TA to monitor the class at the remote campus, Edinburg campus, during the lecture in case any technology problem occurs such as projector screen not receiving any signal or the speaker not working. The TA also proctored the midterm and final exams of an ITV course.

\section{Exams, projects and assignments strategy}

The instructors for the ITV courses assigned homework exercises to students on weekly basis to help the students practice the material to enhance understanding of the material. Each ITV course has two exams, midterm and final, both of which cover the same material as homework assignments. They provide students a way to demonstrate that they have learned the knowledge presented in the course and that they have achieved the expected learning outcomes. Complementing the homework assignments and exams, the course also required students to complete several programming projects to hone their hands-on skills and the ability to apply the concepts, methodologies, and algorithms they learned in class to real-world problems and produce functional software tools.

Grade distribution of the above components is as follows:

40\% Homework and Projects

$25 \%$ for each Exam

Projects assigned in the two courses:

- An intelligent vacuum cleaner simulator,

- a puzzle solver, and

- a text classifier.

\section{Overall feedback from students' evaluations}

\section{CSCI-4350 Artificial Intelligence:}


- Positive issues:

- Subject is interesting.

- The instructor explains everything well, is very patient and willing to spend extra time to explain difficult concepts.

- Negative issues:

- Grading might need more clarifications.

- Course pace might be a little fast especially given the amount of material covered.

\section{CSCI-4301 Digital Image Processing:}

- Positive issues:

- Dr. has great knowledge over Digital Image Processing. He manages to be able to relate to each subject and make it easy to understand as the semester goes on. Although as always, even though it is an elective class, he still finds a way to push you to the direction that will put you uneasy but will thank him for it later. I recommend anyone to take his class as long as they are ready to put in the work.

- Excellent professor. Lectures are engaging and interesting. Projects are challenging and rewarding as they improve your computer skills.

- Good class would like a computer vision course offered by you for undergraduates.

- Knowledgeable, patient, accessible, and overall agreeable professor.

- Learned a lot about image processing. Really enjoyed not just learning to topics from image processing, but also how its applied in computer science

- The course did a great job at introducing the topic of DIP. Everything we covered was fun and enjoyable and it helped spark an interest in the topic.

- learned a lot of great skills in digital image processing. thank you Dr.!

- Dr. provided an effective course on image processing. His experience made him well versed in the topics we covered in class.

- Negative issues:

- Replies promptly to email. Lost track of time towards the end of the semester and seemed to give less and less instructions for project. As though the instructor was procrastinating on doing the same project as the students.

- Good class would like a computer vision course offered by you for undergraduates.

\section{Any major glitches or obstacles}

- At the beginning of the course, the microphone was not working consistently, making it difficult for the instructor to deliver the lecture; sometimes the instructor had to repeat part of the lecture so that the students at the remote campus could hear and understand.

- Video quality and sound issues were identified and fixed at the beginning of the class. 


\section{Suggestions for improvements}

- Even though the microphone issue described above was eventually solved, the instructors feel that to ensure the quality of ITV courses it is critical that the university provide sufficient technical support to make sure that classroom technology does not become an obstacle for effectively delivering ITV courses. This should include equipping ITV classrooms with high-quality video and audio devices along with standby technicians who are able to fix any technical issues on the spot.

- Some students in these ITV courses who attended the lectures remotely desired that the instructor held in-person office hours at the remote campus weekly as they prefer face-toface discussion rather than over ITV. The instructors believe that most students, and even the instructors, would feel the same way. However, to implement this practice, an ITV instructor needs to devote significantly more time and effort, and in particular to the travel time between campuses. Such effort should be recognized by the university, otherwise, it simply won't be fair to ITV instructors and, therefore, ITV delivery method will not be sustainable.

\section{Conclusions and Future Work}

Based on students' feedback and our overall analysis, we believe that ITV courses provide a viable solution to distributed campuses that are geographically dispersed and suffer from logistics, scheduling, enrollment, and expertise issues. ITV come very close to the face-to-face ideal of teaching, and by alternating instruction, the students on both campuses enjoy the convenience and comfort of being on campus while taking the courses they desire or the professor they prefer. While the burden is shifted to the instructor, providing teaching help (grading, tutoring, office hours, etc.), workload incentives, and IT technologies to an ITV instructor is a practical way to optimize course offering at multiple campuses.

More assessment will be needed as we offer more courses and obtain a more statistically significant sample of courses and students.

\section{Acknowledgment:}

The instructors offer a special thanks to the students in the two explored classes for providing feedback, formal and informal, throughout the semester. We also would like to thank the IT department at the Brownsville campus for working on all the technical issues from the Brownsville campus. 


\section{References}

[1]. Lesley McBain, "College and University Mergers: An Update on Recent Trends," Policy Matters, A Higher Education Policy Brief of the American Association of State Colleges and Universities,www.aascu.org/policy/publications/policymatters/2012/collegemerg ersupdate.pdf. May (2012).

[2]. Oblinger DG, Barone CA, Hawkins BL. (2001). Distributed education and its challenges: An overview. Washington, DC: American Council on Education

[3]. A Stella, A Gnanam, "Quality assurance in distance education: The challenges to be addressed," Higher education, 2004 - Springer

[4]. Martha May Tevis, "Reflections on the Termination of Two Universities and the Creation of a New University," Journal of Philosophy \& History of Education, vol. 65, no. 1, 2015, pp. $109-122$

[5]. Bonwell, C., and Eison, J. Active Learning: Creating Excitement in the Classroom. ASHEERIC Higher Education Report 1, 1991.

[6]. Quweider, MK and Khan, Fitra "Implementing a Challenge-based Approach to Teaching Computer Graphics in Computer and Information Sciences," ASEE-2016 conference, New Orleans, LA.

[7]. Quweider, MK and Khan, Fitra "Visualization as Effective Instructional and Learning Tools in the Computer Science Curriculum," ASEE-2017 conference, June 25 - 28, 2017, Columbus, Ohio. Presented at CoED: Computer Science Topics 